\title{
Association between preeclampsia and prostasin polymorphism in Pakistani females
}

Saima Ejaz, M.Phil, PhD, Anwar Ali, MSc, PhD, Kamran Azim, M.Phil, PhD, AtifMahmood, MBBS, M.Phil, Asif I. Khan, MSc, M.Phil, Tuline A. Almazyad, MBBS, Bushra Bilal, M.Phil, PhD.

\begin{abstract}
الأهداف : للبحث عن العلاقة ما بين تعدد الأشكال الجيني لجين البروستاسين وحدوث مقدمات الارتعاج عند نساء دولة ماند بين نعدد الاكستان.

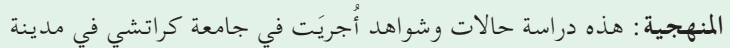

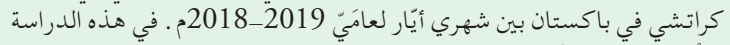

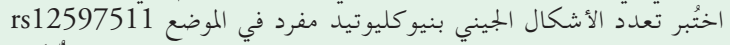

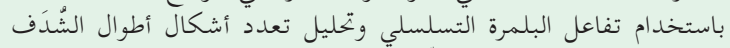

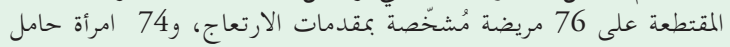
ذوات ضغط دم طبيعي. النتائج: لاحظنا زيادة كبيرة في خطر الإصابة بمقدمات الارتعاج المرتبطة

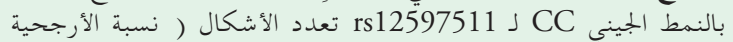

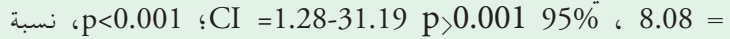
الأرجحية=14.66 و 95\% CI=3.31-65.07 ) بالمقارنة إلى ناقلات الأنماط

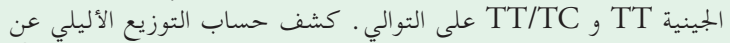

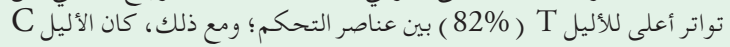

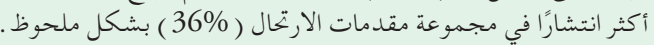

الحخلاصة : : إذًا التكرار المُعتدّ بشكل أكبر للأليل 'C' في جئ جين البروستاسين

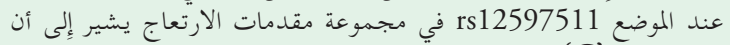

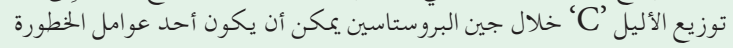

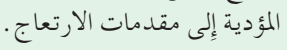

Objectives: To investigate the relationship between a prostasin gene variations and the development of preeclampsia in a Pakistani female population.

Methods: This was a case-control study carried out at University of Karachi, Karachi, Pakistan between May 2018 and 2019. A single nucleotide polymorphism (SNP) at rs12597511 locus was examined with polymerase chain reaction (PCR) and restriction fragment length polymorphism (RFLP) analyses in 76 preeclamptic and 74 normotensive expecting mothers.

Results: We observed significantly increased risk of preeclampsia associated with the CC genotype of rs12597511 polymorphism as compared to TT $(p<0.001, \quad \mathrm{OR}=8.08,95 \%$ CI: $1.28-31.19)$ and TT/TC $(p<0.001, \mathrm{OR}=14.66$ and $95 \%$ CI: 3.31 -
65.07) genotypes carriers. Calculation of the allelic distribution revealed a higher frequency of the $\mathrm{T}$ allele (82\%) among controls; however, the $\mathrm{C}$ allele was more prevalent in the preeclamptic group (36\%) significantly.

Conclusion: The significantly higher $\mathrm{C}$ allele frequency in the prostasin gene at the rs12597511 locus in the preeclamptic group indicates that the distribution of the $\mathrm{C}$ allele of the prostasin gene is a potential risk factor contributing to the development of preeclampsia.

Keywords: hypertension, preeclampsia, prostasin, epithelial sodium channel

Saudi Med J 2020; Vol. 41 (11): 1234-1240 doi: 10.15537/smj.2020.11.25497

From the Department of Physiology (Ejaz, Almazyad), King Saud Bin Abdulaziz University of Health Sciences, Riyadh, Kingdom of Saudi Arabia, from the Department of Physiology (Ali), University of Karachi, from the Department of Bioscience (Azim, Bilal), Muhammad Ali Jinnah University, from the Department of Pathology (Khan), Dow University of Health Sciences, Karachi, and from the Department of Physiology (Mahmood), Bhitai Medical and Dental College, Mirpur Khas, Pakistan.

Received 15th August 2020. Accepted 15th October 2020.

Address correspondence and reprint request to: Dr. Saima Ejaz, Department of Physiology, King Saud Bin Abdulaziz University of Health Sciences, Riyadh, Kingdom of Saudi Arabia. E-mail: saimaejaz84@outlook.com

ORCID ID: https://orcid.org/0000-0003-1068-3602

$\mathrm{P}$ reeclampsia (PE) is among the most devastating maternal conditions. It sometimes further develops into eclampsia, a severe and potentially life-threatening complication characterized by seizures, resulting in fetal and maternal morbidity and mortality. ${ }^{1}$ It complicates approximately $5-7 \%$ of all pregnancies and each year it causes more than 500,000 fetal and 70,000 maternal deaths worldwide. ${ }^{2}$ In comparison, women have 
higher risks of $\mathrm{PE}$ in developing countries than in developed countries, due to low socioeconomic status and less facilities available. In Pakistan, it accounts for approximately $5 \%$ of all cases of pregnancy. ${ }^{3}$ Preeclampsia occurs due to shallow invasion of trophoblast cells, which results in abnormal placental vascular remodeling, placental hypoxia, and ischemia, leading to vascular endothelial cell damage. ${ }^{4}$ The invasion of trophoblast cells may be caused by altered gene expressions associated with tumor invasion, which may occur during placentation. Despite the existence of a broad spectrum of research, the pathophysiology of this disorder is still not fully understood. Furthermore, no effective prevention has been discovered so far; the treatment that exists is only limited to symptomatic relief.

Many studies have been performed to identify preeclamptic susceptibility genes and their polymorphisms, but there have rarely been consistent results. ${ }^{5,6}$ The majority of scientists found a weak association, if any, and further confirmation was required in most of those studies. Some studies suggested that prostasin, a serine protease acts on the distal nephron, provides a novel mechanism in blood pressure regulation. Prostasin maintains blood pressure through the activation and proteolytic processing of the epithelial sodium channel $(\mathrm{ENaC}){ }^{7}$ The epithelial sodium channel is expressed in the distal renal tubules and consists of 3 subunits, $\alpha, \beta$, and $\gamma$. Although, sodium reabsorption by $\mathrm{ENaC}$ accounts for a comparatively small proportion $(<5 \%)$, but it is the rate-limiting step and involved in final renal adjustment to sodium balance, ultimately regulating blood pressure. ${ }^{8}$ Prostasin is believed to cause breakage of an inhibitory peptide from $\gamma$-ENaC in order to activate it intracellularly. ${ }^{9,10}$ Studies on preeclamptic patients have also revealed that prostasin expression is present in the villi of primate and human placental cell lines. ${ }^{11,12}$ Abnormal expressions of prostasin were found to be closely related to tumor invasion development, and metastasis. ${ }^{13}$ Human prostasin (PRSS8) is located at 16p11.2 and consisting of 5 introns and 6 exons; comprised a genomic region of 7 kilobase $(\mathrm{kb}) .{ }^{14} \mathrm{Li}$ et al, ${ }^{15}$ demonstrated a significant association of prostasin gene variation (at E342K) in Xinjiang Kazakh hypertensive population and proposed to observe the same in other populations with a larger sample size. Another study identified a

Disclosure. Authors have no conflict of interests, and the work was not supported or funded by any drug company. significant association between severe preeclampsia and prostasin gene locus rs12597511 in a cohort of Han Chinese women. The authors concluded that C allele of prostasin gene (at rs12597511) might be a contributing factor for severe preeclampsia in Chinese Han women. They postulated that the possible pathogenic mechanism involved the role of prostasin in the invasion of trophoblast cells; prostasin results in a shallow invasion of trophoblast cells and, eventually, causes preeclampsia. ${ }^{16}$ Further activation of $\mathrm{ENaC}$ by prostasin increases the reabsorption of water and $\mathrm{Na}+$ in the kidneys, ultimately leading to hypertension. ${ }^{17}$ The differences in results of different studies demonstrated racial differences of prostasin polymorphism and indicated the need for further research with greater sample sizes involving other ethnicities.

Therefore, in this paper, the Pakistani population was added hopefully to contribute to the understanding of genetic variations associated with preeclampsia. There have been increased morbidity and mortality rates of mothers with preeclampsia in Pakistan, which makes it particularly important to study the prostasin gene.

The current study proposes an evaluation of genetic variations of the prostasin gene at rs12597511 in preeclamptic females, which may have significant implications on the clinical approach to preeclampsia. The identification of gene variants responsible for preeclampsia will increase our understanding of molecular mechanisms of this condition and, therefore, facilitate the development of effective methods for early intervention and prevention of preeclampsia.

Methods. This is a case-control study performed on preeclamptic Pakistani women who attended outpatient departments and gynecology wards in the civil hospital and Dow University Hospital Ojha campus, Karachi, Pakistan. Institutional review board of Dow University of Health Sciences approved the research (IRB/657/ DUHS/Approval/2015/788), where all principles of Helsinki, 2013 were followed. Benchwork was executed at Muhammad Ali Jinnah University (MAJU), Pakistan from 2018-2019.

The total sample size of 150 (control;74, preeclamptic; 76) was calculated using Rao soft sample size calculator. Subjects with a medical history of hepatic or kidney diseases, diabetes, hypercholestrolemia, and heart failure were excluded from the study. The control group included pregnant females with systolic BP of $<140$ $\mathrm{mm} \mathrm{Hg}$ and diastolic BP of $<90 \mathrm{~mm} \mathrm{Hg}$, who were not receiving hormone replacement therapy or treatment for heart disease during the time of the study. The other group included previously diagnosed preeclamptic 
females with no known history of diabetes, renal, and heart diseases. The diagnostic criteria for preeclampsia were high blood pressure $(\geq 140 / 90 \mathrm{~mm} \mathrm{Hg})$ in the presence or absence of proteinuria ( $\geq 1+$ on dipstick) after 20 weeks of gestation. If the latter was the case, then at least one or more of the following symptoms had to be present; impaired hepatic function, reduced platelet count, pulmonary edema, reduced renal function, new-onset headache and visual disturbance. The control group was labelled as group I and the preeclamptic as group II. All subjects were aged between 20-40 years. They were selected after the written consent was obtained, where possible benefits and risks associated with participation in the study were explained in detail, and data confidentiality was assured. A detailed medical history was obtained with the help of a questionnaire, and a thorough physical examination was carried out to rule out the presence of any disease. The weight prior to pregnancy was obtained verbally upon the first antenatal visit.

Five microliters of blood were drawn from subjects' cubital veins. After low-speed centrifugation, the precipitated blood cells were preserved at $-20^{\circ} \mathrm{C}$ for genomic DNA extraction. The ISO-certified Dow diagnostic research and reference laboratory and bioscience laboratory at MAJU were used for storage and bench work.

SNPs genotyping analysis. DNA was isolated through the DNA extraction kit in accordance with the manufacturer's instructions (QIAamp DNA Mini Kit; Cat No./ID: 51306). Genotyping was carried out using the polymerase chain reaction (PCR) amplification method in an automated thermal cycler (Agilent Technologies; Sure cycler 8200). The following predesigned primer pair was used for amplification: ${ }^{15}$

Forward: 5'-TCCCCATCCTTACTGTCTGG-3'. Reverse: 5'-GTTGTGGACTCCGGAACAAT-3'.

The PCR reagent mix was prepared by adding $1 \mu$ of each primer, $5 \mu$ l of the DNA sample, $12.5 \mu$ of master mix, and distilled water to make a total volume of $25 \mu \mathrm{l}$. The process began with a 10 -second denaturation step with temperature of $95^{\circ} \mathrm{C}$, one-minute annealing step with temperature of $55^{\circ} \mathrm{C}$, and finally, a 7 -minute elongation step with temperature of $72^{\circ} \mathrm{C}$. Each step was cycled 43 times. For further genotyping, the PCR products were analyzed using RFLP. As per the manufacturer's instructions, Bsl-1 restriction enzyme was utilized for the digestion of all amplified products. Later, the enzyme-digested products were run on $6 \%$ agarose gel added with $0.5 \mathrm{ug} / \mathrm{ml}$ ethidium bromide at 750 volts for 25 minutes. The results were observed and photographed under UV light using the UVITEC system (Uvitec Cambridge) available at the Bioscience Lab, MAJU.

Statistical tests. The statistical Package for Social Sciences (SPSS), version 23 (IBM Corp., Armonk, NY, USA) was used for statistical analyses. Genotypes and the allele frequency distribution (case/control) were analyzed using the Pearson Chi-square test. Student's t-test was used to compare the mean values of the clinical characteristics (continuous variables) of the control and preeclamptic groups. The Hardy Weinberg equilibrium (HWE) was estimated to determine the genotype distribution between cases and controls. Binary logistic regression analysis was used to evaluate the association between the prostasin gene polymorphism and risk of preeclampsia between alleles and genotypes, via calculation of odds ratios (OR) at $95 \%$ confidence intervals ( $95 \% \mathrm{CI})$. Five multiple inheritance models were used to find association between prostasin gene polymorphism and for coding the SNP effect: dominant, recessive, co-dominant, over dominant. ${ }^{18}$ The reference category was assigned as being the most common homozygous genotype in the control population.

Results. Baseline and clinical characteristics of preeclamptic and healthy pregnant females are presented in Table 1. Our analysis revealed significantly higher $(p=0.005)$ pre-pregnancy body mass index (preBMI); mean systolic and diastolic blood pressure $(p<0.001)$ in preeclamptic females as compared to control group. The observations on study samples with respect to pregnancy weeks revealed that the majority of women were in their third trimester (Table 1).

Genotyping data. Overall, a PCR product of 185 bp was obtained (Figure 1). The RFLP analysis was executed for all samples; prostasin polymorphism at rs12597511 was recognized by the Bsl-I enzyme. After electrophoresis on 6\% agarose gel, the DNA with genotype TT appeared as a single band of $185 \mathrm{bp}$; genotype TC as 3 bands of 185, 112, and $73 \mathrm{bp}$; and genotype CC as 2 bands of 112 and 73 bp (Figure 2).

The rs12597511 genotypic frequencies of TT, CC, and $\mathrm{TC}$ between the control and preeclamptic group are illustrated in Table 2. We observed significantly increased risk of preeclampsia associated with the CC genotype of rs12597511 polymorphism in a co-dominant model $(p<0.001, \mathrm{OR}=8.08,95 \% \mathrm{CI}$ : $1.28-31.19)$ as well as in a recessive model $(p<0.001$, $\mathrm{OR}=14.66$ and $95 \% \mathrm{CI}: 3.31-65.07)$ when compared with TT and TT/TC genotypes carriers, respectively. In addition, TC genotype showed a significantly decrease 
Table 1 - Demographics and clinical characteristics of control and preeclamptic females.

\begin{tabular}{lccc}
\hline Characteristics & Control (n=74) & $\begin{array}{c}\text { Preeclamptic females }(\mathbf{n}=76) \\
\text { Mean } \pm \text { SD }\end{array}$ & $P$-value \\
\hline Age (years) & $24.41 \pm 3.29$ & $32.31 \pm 5.4$ & $0.02^{*}$ \\
PreBMI (kg/m $)$ & $23.61 \pm 2.93$ & $30.44 \pm 5.3$ & $0.005^{* *}$ \\
SBP $(\mathrm{mm} \mathrm{of} \mathrm{Hg)}$ & $127.73 \pm 4.7$ & $158.87 \pm 16.3$ & $<0.001^{* * *}$ \\
DBP (mm of Hg) & $89.75 \pm 2.66$ & $101.92 \pm 11.05$ & $<0.001^{* * *}$ \\
Pregnancy weeks & $33.97 \pm 1.90$ & $35.4 \pm 3.84$ & $0.04^{*}$ \\
\hline SBP - systolic blood pressure, DBP - diastolic blood pressure, SD - standard deviation. ${ }^{*}$ significant at $p<0.05 .^{* *}$ significant at $p<0.01$. \\
\hline
\end{tabular}

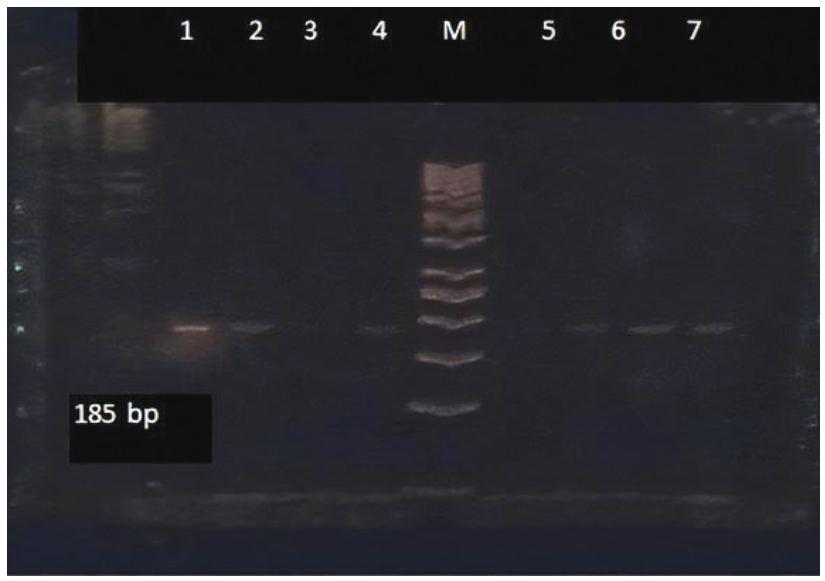

Figure 1 - Gel electrophoresis of 185 bp fragment of prostasin gene polymorphism in $6 \%$ agarose gel.

risk of preeclampsia by $52 \%$ in the codominant model and $56 \%$ in the over dominant model $(p=0.04$; $\mathrm{OR}=0.44$, 95\% CI: 0.20-0.98).

Calculation of the allelic distribution revealed a higher frequency of the $\mathrm{T}$ allele (82\%) among controls; however, the $\mathrm{C}$ allele was more prevalent in the preeclamptic group (36\%). The regression analysis for the allelic frequency showed a significant association $\left(x^{2}=6.18 ; p=0.02\right)$ of the $\mathrm{T}$ and $\mathrm{C}$ alleles, with an odds ratio of 0.39 for $\mathrm{T}$ (CI: $0.18-0.86$ ) and 2.55 for the $\mathrm{C}$ allele (CI: 1.16-5.63). In other words, subjects with the $\mathrm{C}$ allele were 2.55 times more likely to develop preeclampsia, in contrast to others with the T allele, who were 0.39 times $(71 \%)$ less likely to get preeclampsia, illustrated in Table 2.

The PreBMI of the subjects was also compared and was noticed to be significantly different $(p=0.024)$, with an adjusted odds ratio of 1.036. In other words, an increase of $1 \mathrm{~kg} / \mathrm{m}^{2}$ in the PreBMI may increase the risk of preeclampsia by $3.6 \%$.

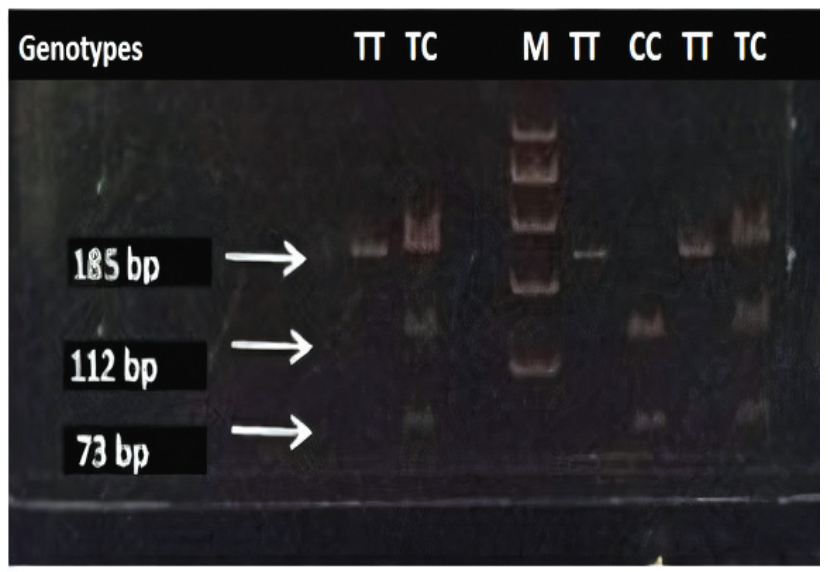

Figure 2 - Gel electrophoresis of PCR-RFLP of prostasin gene polymorphism in $6 \%$ agarose gel with Bsl-I enzyme.

Discussion. Recently, several loci of the prostasin gene have been linked with blood pressure and related phenotypes. Tumorigenesis and metastasis were also found to be correlated with the prostasin gene. Expression loss could have functional implications for tumor invasion and chemotherapy resistance. ${ }^{19}$ Proliferation, differentiation, and invasion of trophoblast cells are closely linked to successful implantation, embryo growth, and placenta formation. ${ }^{20}$ To some extent, it is accepted that severe invasion of trophoblast cells and improper remodelling of the spiral artery results in preeclampsia, which together causes placental hypoxia that ultimately leads to the manifestation of maternal diseases. The expression of prostasin was found in the trophoblast column, the trophoblast shell, and the placental villi of human beings. ${ }^{21}$ Dong et al,,${ }^{16}$ confirmed significantly higher prostasin expressions in the placenta of severe preeclampsia patients in comparison to normal pregnant females.

In view of the role of prostasin in the blood pressure manifestation and tumor invasion, it is judicious to 
Table 2 - Allele and genotype association between preeclampsia cases and controls with the prostasin polymorphism at rs12597511.

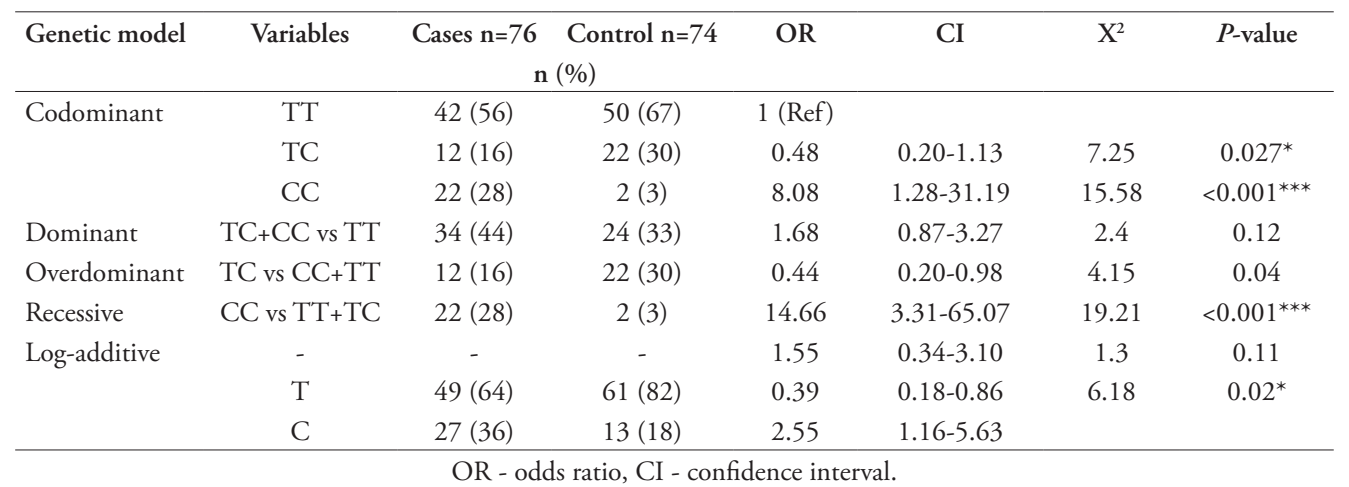

hypothesize that prostasin may be engaged in the development and pathogenesis of preeclampsia, a multifactorial syndrome influenced by environmental, genetic, or other factors. This study investigated the association of prostasin gene polymorphism at rs12597511 in preeclamptic patients among Pakistani females. The principal reason for performing this study was the high maternal-fetal morbidity and mortality rates in developing countries like Pakistan, which causes a significant burden on public healthcare services. However, the exact pathophysiology of the disease remains unclear.

Our study revealed significant differences $(p=0.024)$ in PreBMI of control and preeclamptic groups females with odd ratio $\mathrm{OR}=1.036$, after adjusting for other parameters. Similar significant results were reported by Mrema et al, ${ }^{22}$ who found a positive association between increasing preBMI and the risk of preeclampsia. The calculated odds ratios after adjustment for overweight women was 1.40 and for obese women was $1.80 . .^{22}$ Savitry et $a l,{ }^{23}$ also presented significant associations in hypertensive and preeclamptic and demonstrated that an increase of $1 \mathrm{~kg} / \mathrm{m}^{2}$ in BMI increases the risk of gestational hypertension by $6 \%$ and preeclampsia by $9 \%$. This is because the adipose tissue produces several inflammatory mediators like tumor necrosis factoralpha (TNF), and interleukin-6 (IL-6), which are linked with worse cardiovascular outcomes and increase morbidity. ${ }^{24}$ These factors label obesity as a risk factor associated with cardiovascular events and preeclampsia; it may also be the reason behind the higher prevalence in our study population.

This study showcases the increased risk of having preeclampsia with advanced age, as reported by many authors in their reviews. ${ }^{25,26}$ Although patients in both groups were age-matched in between 20-40 years, but even in this range we found older age females in the preeclampsia group $(p<0.02)$ as compared to the control group which shows that elder age is a risk factor for preeclampsia. Similar results were shown by Dong et al. ${ }^{16}$ However, Gupta et al, ${ }^{27}$ and Priyadarshini et al, ${ }^{28}$ observed no significant differences between the mean gestational age of patients and controls. This discordance may be because the latter study only included subjects having gestational ages higher than 20 weeks.

We observed a noteworthy significant association of rs12597511 C allele with an increased risk of preeclampsia. Primary evidences were shown by CC genotype (compared with TT and TT/TC genotypes), which was significantly more frequent in patients with preeclampsia. Moreover, TC genotype (compared with TT/CC genotypes) frequencies were significantly higher in control and thus, revealed a protective role. Regression analysis for the allelic frequency in the control and preeclamptic groups showed a significant difference $(p=0.02)$ with an odds ratio of 0.39 for the $\mathrm{T}$ alleles and 2.55 in $\mathrm{C}$ alleles. This indicates that preeclamptic females with $\mathrm{C}$ alleles are 2.55 times more likely to get the disease. Conversely, those with the $\mathrm{T}$ allele are 0.39 times (71\%) less likely to get preeclampsia. These results were similar to the study carried out by Dong et $\mathrm{al},{ }^{16}$ where an odds ratio of 2.086 was obtained in the preeclamptic group; however, they combined the frequencies of CC and TC genotypes together due to the low frequency of the CC genotype.

In another study, Zhu et al, ${ }^{29}$ demonstrated prostasin polymorphisms at rs $1549294(\mathrm{C} / \mathrm{T})$, rs2855475, and rs 12597511 SNP in 2 different ethnic populations (African American and European American). They found significant findings only with rs12597511 SNP and they identified the $\mathrm{T}$ allele as a risk factor for hypertension. ${ }^{29}$ The differences within specific alleles 
of the prostasin gene were probably due to the change in ethnicity of subjects in the present study; therefore, further studies are required to validate findings with these ethnicities.

The results suggest that genotypic frequencies in preeclamptic population were not consistent with HWE, having a $p<0.001 \quad\left(x^{2}=30.55\right)$. This indicates that there might be an evolution since preeclampsia is a complex disorder, with multiple environmental factors playing a role in its etiology in addition to genetic variation.

Hence, it could be postulated from the present study that the CC genotype (C allele of rs12597511), being the minor allele, could be a risk factor of preeclampsia in Pakistani females. The genetic variation in the prostasin gene may cause release of an inhibitory peptide from $\mathrm{\gamma}-\mathrm{ENaC}$ in a prostasin-dependent manner. This results in increased channel gating or open state probability. The activation of $\mathrm{ENaC}$ augments tubular sodium reabsorption in the distal nephron, leading to extracellular volume expansion and, eventually, causing hypertension. Moreover, prostasin involvement in the invasion of trophoblast cells results in shallow invasion, which ultimately causes preeclampsia. Further research is required to elucidate precise molecular mechanisms of prostasin in the pathophysiology of preeclampsia. To summarize, this study added data from the Pakistani population to other ethnicities available in the literature on human prostasin gene variations at rs12597511 in preeclamptic women. Finding the causative genes of preeclampsia is of high importance and will hopefully help identify women at risk of cardiovascular diseases and adverse events.

Study limitations. First, patients' samples were only collected from Sindh Province. The association between prostasin gene at rs12597511 and preeclampsia should be replicated in a larger sample size composed of different ethnic groups all over Pakistan as well as in other countries. Second, the study was restricted to only one SNP site (rs12597511) of the prostasin gene, giving information only at that SNP site. In the future, whole genome sequencing should be undertaken to evaluate the relationship between preeclampsia and the prostasin gene. Finally, some inaccuracies may exist since participants were asked to state their pre-pregnancy weight during an interview at the first antenatal care visit, namely, verbally.

In conclusion, this study demonstrates a close relationship between rs12597511 prostasin polymorphism and preeclamptic females in the Pakistani population. Women who carried the $\mathrm{C}$ allele were at a higher genetic risk of being affected by preeclampsia. Personalized medicine designed to match the physiological conditions of patients possessing this genotype could safely and effectively help control the disease.

Acknowledgment. The authors gratefully acknowledge Dr. Emad Masaudi and Dr. Nazish, Biostatician at King Saud Bin Abdulaziz University (KSAU), Riyadh, Kingdom of Saudi Arabia for their efforts in data analysis and Dr. Nada Saleh at KSAU for proofreading the manuscript for publication. Further, the authors would like to thank PaperTrue Editors (www.papertrue.com) for English language editing.

\section{References}

1. Mayrink J, Costa ML, Cecatti JG. Preeclampsia in 2018 : revisiting concepts, physiopathology, and prediction. Scientific World Journal 2018; 2018: 6268276.

2. Rana S, Lemoine E, Granger JP, Karumanchi SA. Preeclampsia: pathophysiology, challenges, and perspectives. Circ Res 2019; 124: 1094-1112.

3. Soomro S, Kumar R, Lakhan H, Shaukat F. Risk factors for pre-eclampsia and eclampsia disorders in tertiary care center in Sukkur, Pakistan. Cureus 2019; 11: e6115.

4. Huang X, Li Z, Lei J, Wang D, Zhang Y. Genetic polymorphism in DGCR8 is associated with late onset of preeclampsia. BMC Med Genet 2019; 20: 151.

5. Nasr AS, El-Azizy HM, Hassan S, Salem H, Diaa N. Interleukin$1 \beta$-gene polymorphisms in preeclamptic Egyptian women. Middle East Fertility Society Journal 2017; 22: 285-289.

6. Armistead B, Kadam L, Drewlo S, Kohan-Ghadr HR. The role of NFKB in healthy and preeclamptic placenta: trophoblasts in the spotlight. Int J Mol Sci 2020; 21: 1775.

7. Szabo R, Bugge TH. Membrane-anchored serine proteases as regulators of epithelial function. Biochem Soc Trans 2020; 48: 517-528.

8. Lossow K, Meyerhof W, Behrens M. Sodium imbalance in mice results primarily in compensatory gene regulatory responses in kidney and colon, but not in taste tissue. Nutrients 2020; 12 : 995.

9. Butterworth MB. Regulation of the epithelial sodium channel (ENaC) by membrane trafficking. Biochim Biophys Acta 2010; 1802: 1166-1177.

10. Carattino MD, Mueller GM, Palmer LG, Frindt G, Rued AC, Hughey RP, et al. Prostasin interacts with the epithelial $\mathrm{Na}+$ channel and facilitates cleavage of the $\mathrm{Y}$-subunit by a second protease. Am J Physiol Renal Physiol 2014; 307: F1080-F1087.

11. Adachi M, Kitamura K, Miyoshi T, Narikiyo T, Iwashita K, Shiraishi N, et al. Activation of epithelial sodium channels by prostasin in xenopus oocytes. J Am Soc Nephrol 2001; 12: 1114-1121.

12. Hummler E, Dousse A, Rieder A, Stehle JC, Rubera I, Osterheld MC, et al. The channel-activating protease CAP1/ Prss8 is required for placental labyrinth maturation. PLoS One 2013; 8: e55796.

13. Zhang L, Jia G, Shi B, Ge G, Duan H, Yang Y. PRSS8 is downregulated and suppresses tumour growth and metastases in hepatocellular carcinoma. Cell Physiol Biochem 2016; 40: 757-769. 
14. Martin TA, Ye L, Sanders AJ, Lane J, Jiang WG. Cancer invasion and metastasis: molecular and cellular perspective [Internet]. Madame Curie Bioscience Database [Update 2013 Accessed 2020 May]. Available from: https://www.ncbi.nlm. nih.gov/books/NBK164700/

15. Li NF, Zhang JH, Chang JH, Yang J, Wang HM, Zhou L, et al. Association of genetic variations of the prostasin gene with essential hypertension in the Xinjiang Kazakh population. Chin Med J (Engl) 2011; 124: 2107-2112.

16. Luo D, Zhang Y, Bai Y, Liu X, Gong Y, Zhou B, et al. Prostasin gene polymorphism at rs12597511 is associated with severe preeclampsia in Chinese Han women. Chin Med J (Engl) 2014; 127: 2048-2052.

17. Chen LM, Chai KX. PRSS8 (protease, serine, 8). Atlas Genet Cytogenet Oncol Haematol 2012; 16: 658-664.

18. Chen H, Zhang Y, Dai L, Song Y, Wang Y, Zhou B, et al. Association between polymorphisms in CXCR2 gene and preeclampsia. Mol Genet Genomic Med 2019; 7: e00578.

19. Red-Horse K, Zhou Y, Genbacev O, Prakobphol A, Foulk R, McMaster M, et al. Trophoblast differentiation during embryo implantation and formation of the maternal-fetal interface. $J$ Clin Invest 2004; 114: 744-754.

20. Abedin Do A, Esmaeilzadeh E, Amin-Beidokhti M, Pirjani R, Gholami M, Mirfakhraie R. ACE gene rs4343 polymorphism elevates the risk of preeclampsia in pregnant women. J Hum Hypertens 2018; 32: 825-830.

21. Fu YY, Gao WL, Chen M, Chai KX, Wang YL, Chen LM. Prostasin regulates human placental trophoblast cell proliferation via the epidermal growth factor receptor signaling pathway. Hum Reprod 2010; 25: 623-632.
22. Mrema D, Lie RT, Østbye T, Mahande MJ, Daltveit AK. The association between pre pregnancy body mass index and risk of preeclampsia: a registry based study from Tanzania. BMC Pregnancy Childbirth 2018; 18: 56.

23. Savitri AI, Zuithoff P, Browne JL, Amelia D, Baharuddin M, Grobbee DE, et al. Does pre-pregnancy BMI determine blood pressure during pregnancy? A prospective cohort study. BMJ Open 2016; 6: e011626.

24. Ness RB, Roberts JM, Lindheimer MD, Roberts JM, Cunningham FG. Chesley's hypertensive disorders in pregnancy, epidemiology of pregnancy-related hypertension. Elsevier (Academic Press) 2016; 6: 37-50.

25. Mol BWJ, Roberts CT, Thangaratinam S, Magee LA, de Groot CJM, Hofmeyr GJ. Pre-eclampsia. Lancet 2016; 387: 999-1011.

26. Henderson JT, Thompson JH, Burda BU, Cantor A, Beil T, Whitlock EP. Screening for preeclampsia: a systematic evidence review for the U.S. preventive services task force [Internet]. Agency for Healthcare Research and Quality (US) 2017; 1405211-EF-1.

27. Gupta A, Bindu SG, Mishra KB, Dubey I. A comparison of platelet count in severe preeclampsia, mild preeclampsia and normal pregnancy. IJRMS 2018; 6: 671-676.

28. Priyadarshini GP, Mohanty RR. Assessment of coagulation profile and its correlation with severity of preeclampsia in women of odisha-a comparative cross-sectional study. Inter J Basic Applied Physiol 2014; 3: 1423-1456.

29. Zhu H, Guo D, Li K, Yan W, Tan Y, Wang X, et al. Prostasin: a possible candidate gene for human hypertension. Am J Hypertens 2008; 21: 1028-1033. 